\title{
Hypoxic vascular response and ventilation/perfusion matching in end-stage COPD may depend on p22phox
}

\author{
Chandran Nagaraj ${ }^{1,2}$, Christoph Tabeling ${ }^{3}$, Bence M. Nagy ${ }^{1,2}$, Pritesh P. Jain ${ }^{1}$, \\ Leigh M. Marsh ${ }^{1}$, Rita Papp ${ }^{1}$, Michael Pienn ${ }^{1}$, Martin Witzenrath $^{3}$, \\ Bahil Ghanim ${ }^{4}$, Walter Klepetko ${ }^{4}$, E. Kenneth Weir ${ }^{5}$, Stefan Heschl ${ }^{6}$, \\ Grazyna Kwapiszewska ${ }^{1,2}$, Andrea Olschewski ${ }^{1,2}$ and Horst Olschewski ${ }^{1,7}$
}

Affiliations: ${ }^{1}$ Ludwig Boltzmann Institute for Lung Vascular Research, Graz, Austria. ${ }^{2}$ Institute of Physiology, Medical University of Graz, Graz, Austria. ${ }^{3}$ Dept of Infectious Diseases and Pulmonary Medicine, Charité Universitätsmedizin Berlin, Berlin, Germany. ${ }^{4}$ Dept of Thoracic Surgery, Division of Surgery, Medical University Vienna, Vienna, Austria. ${ }^{5}$ Dept of Medicine, University of Minnesota, Minneapolis, MN, USA. ${ }^{6}$ Dept of Anaesthesiology and Intensive Care Medicine, Medical University of Graz, Graz, Austria. ${ }^{7}$ Division of Pulmonology, Dept of Internal Medicine, Medical University of Graz, Graz, Austria.

Correspondence: Andrea Olschewski, Ludwig Boltzmann Institute for Lung Vascular Research, Medical University of Graz, Stiftingtalstrasse 24, Graz-8010 Austria. E-mail: andrea.olschewskidlvr.lbg.ac.at

@ERSpublications

In COPD, p22phox controls hypoxic pulmonary vascular response and ventilation-perfusion matching http://ow.ly/9Koo30aWMmT

Cite this article as: Nagaraj C, Tabeling C, Nagy BM, et al. Hypoxic vascular response and ventilation/perfusion matching in end-stage COPD may depend on p22phox. Eur Respir J 2017; 50: 1601651 [https://doi.org/10.1183/13993003.01651-2016].

ABSTRACT Chronic obstructive pulmonary disease (COPD) is a heterogeneous disease in which the amount of emphysema and airway disease may be very different between individuals, even in end-stage disease. Emphysema formation may be linked to the involvement of the small pulmonary vessels. The NAPDH oxidase (Nox) family is emerging as a key disease-related factor in vascular diseases, but currently its role in hypoxia-induced pulmonary remodelling in COPD remains unclear.

Here we investigate the role of p22phox, a regulatory subunit of Nox, in COPD lungs, hypoxic pulmonary vasoconstriction (HPV), hypoxia-induced pulmonary vascular remodelling and pulmonary hypertension.

In COPD, compared to control lungs, p22phox expression was significantly reduced. The expression was correlated positively with mean pulmonary arterial pressure and oxygenation index and negatively with the diffusing capacity of the lung for carbon monoxide $(p<0.02)$. This suggests a role of $p 22 p h o x$ in

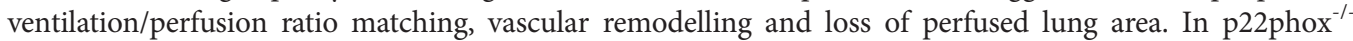
mice, HPV was significantly impaired. In the chronic hypoxic setting, lack of p22phox was associated with improved right ventricular function and decreased pulmonary vascular remodelling.

p22phox-dependent Nox plays an important role in the COPD phenotype, by its action on phase II HPV and chronic vascular remodelling.

This article has supplementary material available from erj.ersjournals.com

Received: Aug 192016 | Accepted after revision: April 102017

Conflict of interest: Disclosures can be found alongside this article at erj.ersjournals.com

Copyright OERS 2017 


\section{Introduction}

Chronic obstructive pulmonary disease (COPD) is a heterogeneous disease. The most divergent COPD clusters may be the chronic bronchitis phenotype with hypoxaemia (blue bloater) and the emphysema phenotype without hypoxaemia (pink puffer), although many other phenotypes can be defined [1]. Even in end-stage pulmonary disease, e.g. in lung transplant candidates, such phenotypes prevail [2]. Emphysema formation has been linked to the involvement of the small pulmonary arteries and the endothelium and could be achieved experimentally using vascular endothelial growth factor antagonists [3] or by chronic smoke exposure [4]. The changes in the small pulmonary arteries are characterised by wall thickening with neomuscularisation and rarefaction of the very distal vessels generally referred to as pulmonary vascular remodelling. Hypoxia-driven pulmonary vascular remodelling is one of the underlying mechanisms, although many other mechanisms may contribute [5]. A characteristic consequence of pulmonary vascular remodelling is pulmonary hypertension, which by itself is associated with shorter survival and worse clinical outcome in COPD and other lung diseases [6].

Hypoxic pulmonary vasoconstriction (HPV) is the mechanism that optimises gas exchange in situations with ventilation/perfusion $\left(V^{\prime} / Q^{\prime}\right)$ mismatch. It redirects blood flow from poorly ventilated areas to well-ventilated areas in the lung, resulting in better oxygenation [7]. HPV can be defined as a rapid, reversible increase in pulmonary vascular resistance caused by contraction of the small muscular pulmonary arteries with an internal diameter of $\sim 200-600 \mu \mathrm{m}$ in humans, in response to physiological levels of hypoxia $[8,9]$. The response to alveolar hypoxia shows a biphasic character, with an early pulmonary arterial pressure (PAP) peak (phase I) and a more protracted secondary pressure elevation (phase II). Chronic hypoxia results in pulmonary arterial remodelling and pulmonary hypertension.

NADPH oxidases (Nox) play an important role as a proposed hypoxia sensor for HPV [10]. The reactive oxygen species (ROS)-generating enzyme Nox has been studied intensively during the past two decades $[11,12]$ and a few recent reports have linked pathological findings to Nox subtypes [13-15].

The p22phox subunit of Nox is particularly intriguing, since it is essential for the function of Nox1-4 proteins by a direct interaction at the protein level. Furthermore, p22phox is required for Nox stabilisation and docking of cytosolic proteins, and thus for the formation of a functional ROS-generating Nox [16].

We hypothesised that p22phox might be associated with $V^{\prime} / Q^{\prime}$ matching in COPD via its effects on HPV and on hypoxia-induced vascular remodelling. Thus, our strategy was to perform investigations on the lungs of clinically well-characterised COPD patients who underwent lung transplantation for end-stage disease and to compare the results to lungs from lung donors without COPD. Furthermore, we used the p22phox knockout mouse to achieve functional inactivity of all p22phox-dependent Nox enzymes. We found that p22phox expression was correlated positively with PAP and oxygenation and negatively with gas exchange capacity, suggesting that these NADPH oxidases may facilitate HPV, but simultaneously might cause pulmonary hypertension and loss of perfused lung area.

TABLE 1 Clinical characteristics of patients with chronic obstructive pulmonary disease (COPD) and healthy donors

Controls

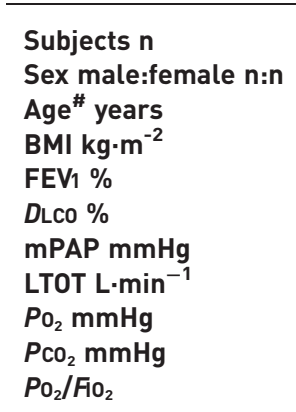

COPD patients

$188(158-216)$

Data are presented as median (interquartile range), unless otherwise stated. BMI: body mass index; FEV1: forced expiratory volume in $1 \mathrm{~s}$; DLCO: diffusing capacity of the lung for carbon monoxide; mPAP: mean pulmonary arterial pressure; LTOT: long-term oxygen therapy; $\mathrm{PO}_{2}$ : oxygen tension; $\mathrm{PCO}_{2}$ : carbon dioxide tension; $\mathrm{FlO}_{2}$ : inspiratory oxygen fraction; NA: not applicable. ${ }^{\#}$ : data are presented as median (range). 
Materials and methods

Full experimental details and methods are deteailed in the online supplementary material.

\section{Results}

Study population

Lung samples from 71 patients with COPD (36 male and 35 female; diagnosis by listing for transplantation) who underwent lung transplantation were collected between June 2011 and December 2015. 31 patients with COPD met the inclusion criteria (clinical parameters and characteristic features of the disease on representative computed tomography (CT) images, as well as measurement of mean PAP by right heart catheterisation within the 6 months prior to lung transplantation) for this study. In addition, control lung tissue from donors without tumours $(n=8)$ was obtained. Patient information is presented in table 1. All subjects suffered from severe or very severe COPD and had significant airway obstruction with a marked reduction in forced expiratory volume in $1 \mathrm{~s}$ (FEV1) (median (interquartile range (IQR)) 20 (16-28)\% predicted) and moderate to severe hypoxaemia. Diffusing capacity of the lung for carbon monoxide (DLCO) was greatly reduced to a mean of 25 (19-32)\% pred. All patients were treated with long-term oxygen therapy. 22 patients had pulmonary hypertension with a mean PAP of 30 (2439) $\mathrm{mmHg}$.

\section{In COPD patients, p22phox is significantly correlated with haemodynamics, oxygenation ratio and} diffusing capacity of the lung for carbon monoxide

To determine whether the p22phox-dependent NADPH oxidases are regulated in COPD in the lung, expression of the NADPH oxidase subunits nox1, nox2, nox4 and p22phox was assessed using real-time PCR. As is evident in figure 1a, in COPD lung tissue, p22phox, nox2 and nox4 expression was decreased as compared with control tissue, while p22phox expression in pulmonary arteries obtained using laser-capture microdissection from COPD lungs was generally lower than in healthy controls (figure $1 \mathrm{~b}$ ). In addition, bronchi obtained by the same methods showed a significant downregulation of p22phox (online supplementary figure S1).

Next, we performed Spearman analysis between the lung tissue p22phox levels and the clinical parameters (figure 2, table 2). In COPD patients, there was a significant positive correlation between p22phox expression and mean PAP, between p22phox and the oxygenation index (oxygen tension $\left(\mathrm{PO}_{2}\right)$ /inspiratory oxygen fraction $\left(\mathrm{FIO}_{2}\right)$ ), the clinical indicator of mismatch, and an inverse correlation between p22phox and DLCO, the clinical indicator of perfused lung area. In contrast, emphysema score was not significantly correlated with mean PAP and DLCO (online supplementary figure S2).

Impaired hypoxic pulmonary vasoconstriction in p22phox ${ }^{-/-}$mice

To identify the role of p22phox in the functional response of the pulmonary circulation to hypoxia,

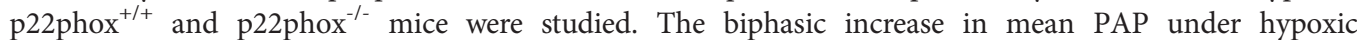

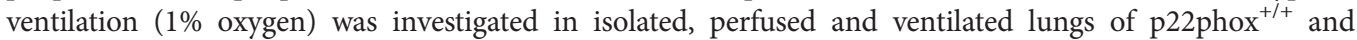

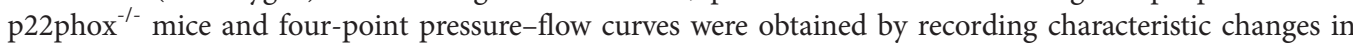
mean PAP during variations in perfusate flow (figure 3a). Lack of p22phox resulted in a skewed HPV response compared to $\mathrm{p}_{2} 2 \mathrm{phox}^{+/+}$littermate controls (figure $3 \mathrm{~b}$ ). Interestingly, the maximum increase in mean PAP in the acute, transient HPV (phase I) was comparable in both groups $\left(6.9 \pm 0.7 \mathrm{cmH}_{2} \mathrm{O}\right.$ versus $7.6 \pm 0.8 \mathrm{cmH}_{2} \mathrm{O}$ for $\mathrm{p}_{2} 2 \mathrm{phox}^{-/-}$and $\mathrm{p} 22 \mathrm{phox}^{+/+}$, respectively), whereas the subsequent sustained HPV

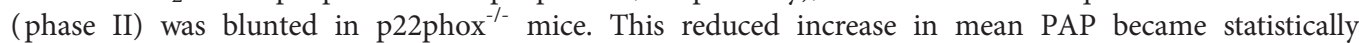
significant at minute 70 and lasted until the end of the measurements. Importantly, these findings were not related to changes in basal mean PAP, which was unaltered in $\mathrm{p} 22 \mathrm{phox}^{-/-}$mice $\left(9.4 \pm 0.3 \mathrm{cmH}_{2} \mathrm{O}\right.$ versus $9.4 \pm 0.3 \mathrm{cmH}_{2} \mathrm{O}$ for $\mathrm{p} 22 \mathrm{phox}^{+/+}$and $\mathrm{p} 22 \mathrm{phox}^{-/-}$, respectively), or to body weight (figure $3 \mathrm{c}$ and $\mathrm{d}$ ). These experiments demonstrate that the lack of p22phox prevented part of the increase in mean PAP during sustained hypoxia and emphasises that the p22phox-dependent NADPH oxidase contributes to the sustained, but not the acute phase I of HPV.

Preserved vasoconstrictor responses of p22phox ${ }^{-/-}$pulmonary arteries to potassium chloride and the thromboxane $A 2$ receptor agonist U46619

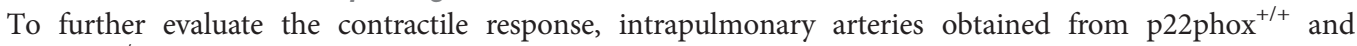

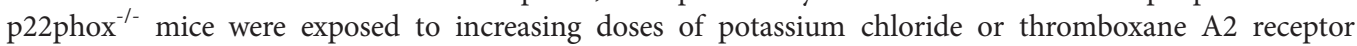
agonist U46619 using a wire myograph. During the cumulative application of these agents, there were no differences in the vasoconstrictor responses between the $\mathrm{p}_{2} 2 \mathrm{phox}^{+/+}$and $\mathrm{p} 22 \mathrm{phox}^{-/-}$mice (online supplementary figure S3A and B). We also examined the tension changes of U46619-preconstricted intrapulmonary arteries to the addition of the potent vasodilator sodium nitroprusside (online 
a)

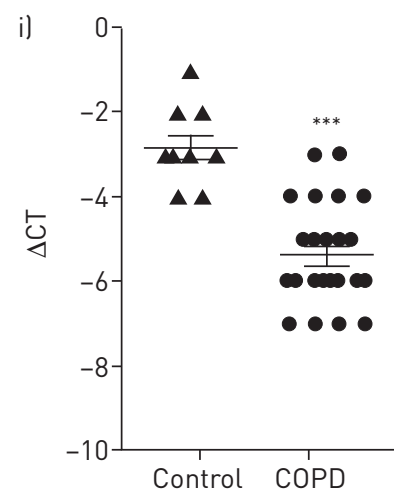

ii)

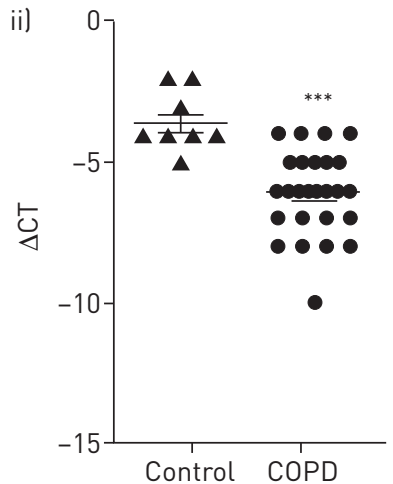

iii)

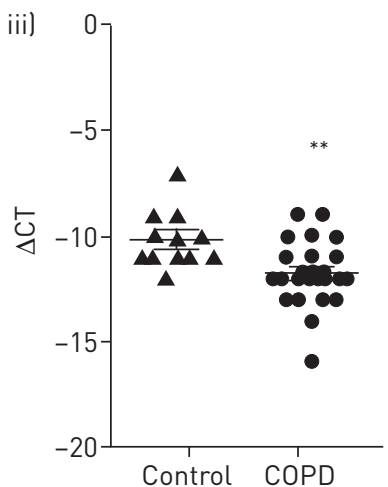

b)

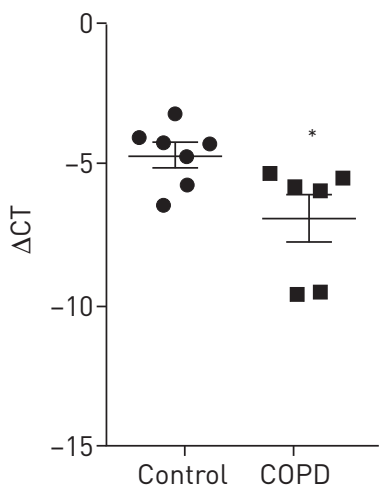

FIGURE 1 Expression of p22phox-dependent NADPH oxidases in human lungs obtained from chronic obstructive pulmonary disease (COPD) patients who underwent lung transplantation. a) Quantitative real-time PCR for i) p22phox, ii) nox2 and iii) nox4 from homogenised human lungs (healthy controls $n=8$ and lungs obtained from COPD patients $n=31$ ). b) Compartment-specific analysis of p22phox expression in pulmonary arteries via laser capture microdissection by quantitative real-time PCR ( $\mathrm{n}=6$ in each group). $\triangle \mathrm{CT}$ : $\mathrm{CT}_{\text {avg }}$ (reference gene) - $\mathrm{CT}_{\text {avg }}$ (target gene). $\mathrm{CT}$ : threshold cycle. ${ }^{*}: \mathrm{p}=0.05 ;{ }^{* *}: \mathrm{p}<0.01 ;{ }^{* * *}: \mathrm{p}<0.001$.

supplementary figure S3C) and found that p22phox deficiency had no effect on the vasodilatory response. These data suggest that p22phox specifically affects pulmonary vascular function related to hypoxia.

Pressure-flow relationship under hypoxia is dependent on p22phox

To directly assess flow-induced changes in mean PAP, isolated perfused and ventilated lungs of p22phox ${ }^{+/+}$and $\mathrm{p} 22 \mathrm{phox}^{-/-}$mice were exposed to a step-wise increase in flow under normoxia, acute HPV (phase I) and sustained HPV (phase II), as visualised in figure 3a. When the flow was increased either under normoxia or during acute HPV, no significant difference could be observed in mean PAP between the $\mathrm{p}_{2} 2 \mathrm{phox}^{+/+}$and $\mathrm{p} 22 \mathrm{phox}^{-/-}$mice (figure 4a). However, at the end of the sustained hypoxic ventilation,

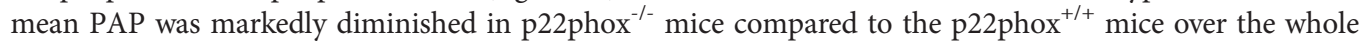
range of the applied perfusion rates (figure $4 \mathrm{~b}$ ).

In addition, pulmonary vascular resistance (PVR), derived from mean PAP at the highest perfusion rate $\left(2.0 \mathrm{~mL} \cdot \mathrm{min}^{-1}\right)$ was analysed. No differences were observed in PVR under basal normoxic ventilation (4.88 $\pm 0.25 \mathrm{cmH}_{2} \mathrm{O} \cdot \mathrm{mL}^{-1} \cdot \mathrm{min}^{-1}$ versus $4.76 \pm 0.28 \mathrm{cmH}_{2} \mathrm{O} \cdot \mathrm{mL}^{-1} \cdot \mathrm{min}^{-1}$ ) (figure $4 \mathrm{c}$ ) or at the end of phase I HPV $\left(7.68 \pm 0.46 \mathrm{cmH}_{2} \mathrm{O} \cdot \mathrm{mL}^{-1} \cdot \mathrm{min}^{-1}\right.$ versus $\left.7.02 \pm 0.27 \mathrm{cmH}_{2} \mathrm{O} \cdot \mathrm{mL}^{-1} \cdot \mathrm{min}^{-1}\right)$ between $22 \mathrm{phox}^{+/+}$and $222 \mathrm{phox}^{-/-}$

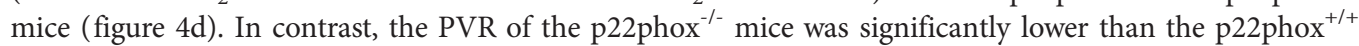
mice during phase II HPV $\left(6.86 \pm 0.32 \mathrm{cmH} \mathrm{H}_{2} \mathrm{O} \cdot \mathrm{mL}^{-1} \cdot \mathrm{min}^{-1}\right.$ versus $8.26 \pm 0.39 \mathrm{cmH}_{2} \mathrm{O} \cdot \mathrm{mL}^{-1} \cdot \mathrm{min}^{-1}$ ) (figure $4 \mathrm{e})$. In order to exclude the possibility that differences in oedema secondary to HPV might interfere with our findings, we determined the wet/dry ratio and the total weight of the lungs at the end of the

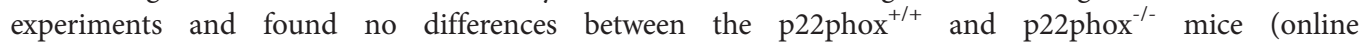
supplementary figure S4A and B).
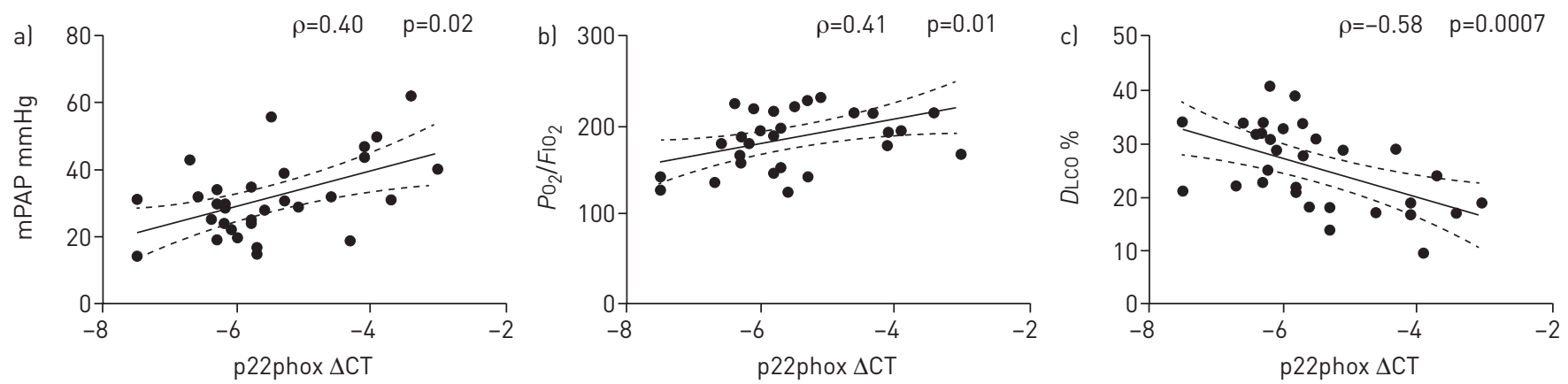

FIGURE 2 Correlation of p22phox levels with clinical parameters of chronic obstructive pulmonary disease (COPD) patients who underwent lung transplantation. p22phox correlation with a) mean pulmonary artery pressure (mPAP); b) oxygenation ratio (oxygen tension $\left(\mathrm{Po}_{2}\right) /$ inspiratory oxygen fraction $\left(\mathrm{F}_{\mathrm{IO}} \mathrm{l}\right)$; and $\mathrm{C}$ ) diffusing capacity of the lung for carbon monoxide $(\mathrm{DLCO})$, the clinical indicator of lung parenchymal damage. $\Delta \mathrm{CT}$ : $\mathrm{CT}$ avg (reference gene) - $\mathrm{CT}_{\text {avg }}$ (target gene). CT: threshold cycle. 
TABLE 2 Spearman correlation coefficients in chronic obstructive pulmonary disease patients

\begin{tabular}{|c|c|c|c|c|c|c|c|c|c|c|c|c|c|c|c|c|c|}
\hline & \multirow[t]{2}{*}{ p22phox } & \multicolumn{2}{|c|}{ mPAP } & \multicolumn{2}{|c|}{ BMI } & \multicolumn{2}{|c|}{ DLco } & \multicolumn{2}{|c|}{ FEV1 } & \multicolumn{2}{|c|}{ LTOT } & \multicolumn{2}{|c|}{$\mathrm{PCO}_{2}$} & \multicolumn{2}{|c|}{$\mathrm{PO}_{2}$} & \multicolumn{2}{|c|}{$\mathrm{Po}_{2} / \mathrm{FiO}_{2}$} \\
\hline & & $\rho$ & $p$-value & $\rho$ & $p$-value & $\rho$ & $p$-value & $\rho$ & $\mathrm{p}$-value & $\rho$ & $\mathrm{p}$-value & $\rho$ & $p$-value & $\rho$ & $p$-value & $\rho$ & $p$-value \\
\hline p22phox & 1 & 0.40 & 0.025 & -0.07 & 0.69 & -0.58 & 0.0007 & -0.03 & 0.89 & -0.35 & 0.05 & -0.02 & 0.90 & 0.33 & 0.06 & 0.41 & 0.02 \\
\hline mPAP & & & 1 & 0.16 & 0.38 & -0.60 & 0.0003 & 0.13 & 0.47 & 0.05 & 0.78 & 0.05 & 0.77 & 0.25 & 0.17 & 0.08 & 0.65 \\
\hline BMI & & & & & 1 & -0.004 & 0.97 & 0.27 & 0.14 & 0.17 & 0.33 & -0.15 & 0.40 & 0.22 & 0.23 & 0.10 & 0.58 \\
\hline DLco & & & & & & & & 0.09 & 0.62 & 0.17 & 0.34 & -0.16 & 0.38 & -0.09 & 0.59 & -0.12 & 0.48 \\
\hline FEV 1 & & & & & & & & & 1 & 0.30 & 0.09 & -0.43 & 0.01 & -0.06 & 0.71 & -0.25 & 0.16 \\
\hline LTOT & & & & & & & & & & & 1 & -0.22 & 0.23 & 0.02 & 0.9 & -0.67 & $<0.0001$ \\
\hline $\mathrm{PCO}_{2}$ & & & & & & & & & & & & & onto & -0.06 & 0.74 & 0.13 & 0.47 \\
\hline & & & & & & & & & & & & & & & 1 & 0.66 & $<0.0001$ \\
\hline $\mathrm{PO}_{2} / \mathrm{FiO}_{2}$ & & & & & & & & & & & & & & & & & 1 \\
\hline
\end{tabular}

mPAP: mean pulmonary arterial pressure; BMI: body mass index; DLCO: diffusing capacity of the lung for carbon monoxide; FEV1: forced expiratory volume in 1 s; LTOT: long-term oxygen therapy; $\mathrm{PCO}_{2}$ : carbon dioxide tension; $\mathrm{PO}_{2}$ : oxygen tension; $\mathrm{FlO}_{2}$ : inspiratory oxygen fraction. 

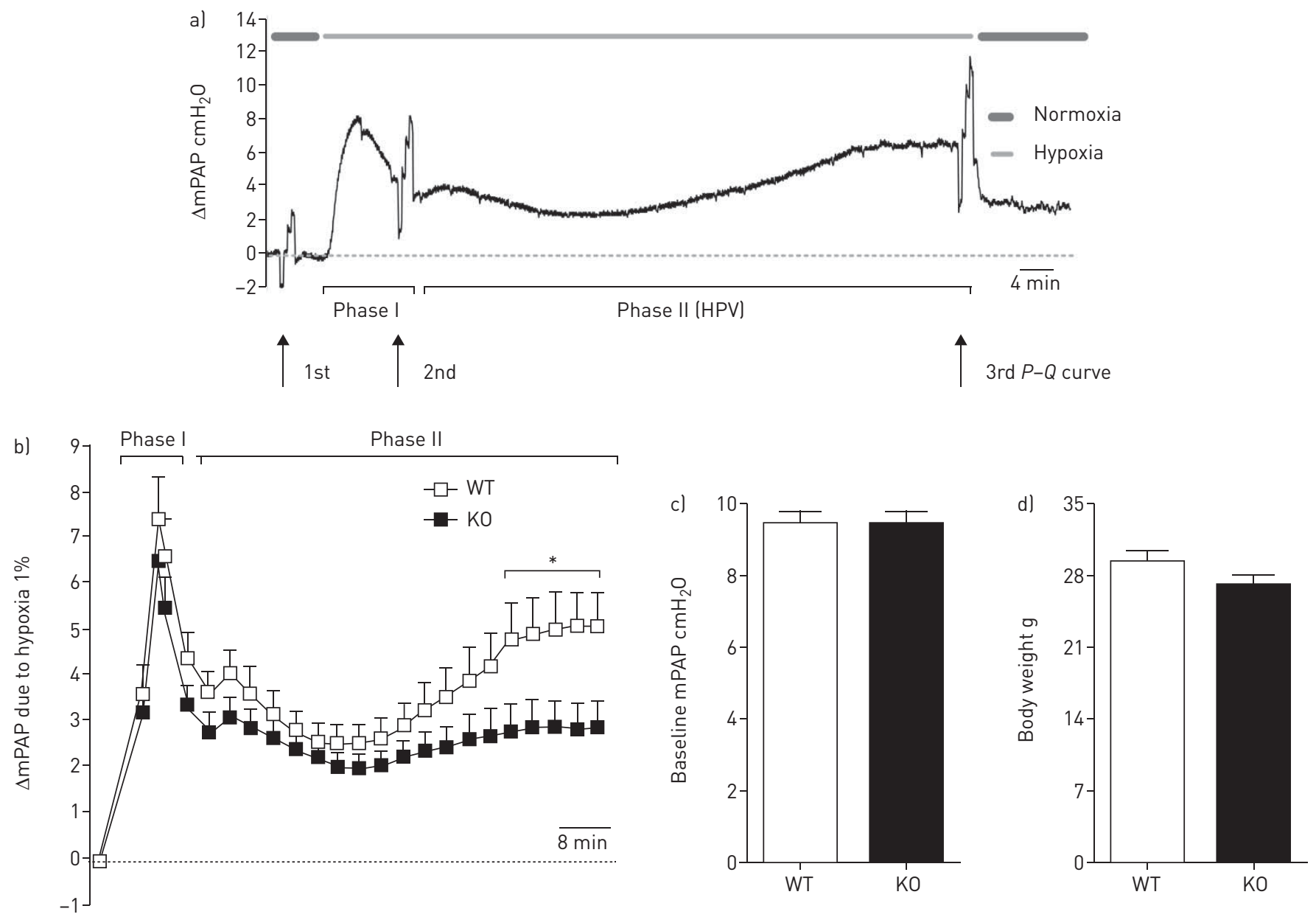

FIGURE 3 p22phox is prerequisite for the sustained phase of hypoxic pulmonary vasoconstriction (HPV). a) An original recording illustrates the biphasic increase in mean pulmonary arterial pressure $(\triangle \mathrm{mPAP})$ in isolated perfused mouse lungs upon hypoxic ventilation (1\% oxygen) showing acute (phase I) and sustained (phase II) HPV. Arrows indicate three different time points for flow-induced pressure changes (P-Q) during the normoxic baseline, HPV phase I and HPV phase II. b) Group data showing HPV response, determined as $\triangle$ mPAP, indicate reduced sustained HPV in p22phox mice. Bar graphs showing no change in c) basal mPAP or d) body weight in $\mathrm{p}^{-/-} 2 \mathrm{phox}^{-/-}$mice. $\mathrm{n}=6$ for $\mathrm{p} 22 \mathrm{phox}{ }^{+/+}$and $\mathrm{n}=8$ for p22phox ${ }^{-/-}$. WT: wild-type; KO: knockout. *: $p<0.05$.

\section{Expression of p22phox in the mouse lung}

To determine the localisation of p22phox, we stained lungs obtained from $\mathrm{p} 22 \mathrm{phox}^{+/+}$and $\mathrm{p} 22 \mathrm{phox}^{-1-}$ mice. As depicted in figure $5 \mathrm{a}$ and $\mathrm{b}$, small and large pulmonary arteries expressed $\mathrm{p} 22 \mathrm{phox}$ in their endothelium and in smooth muscle cells. Furthermore, p22phox was present in the epithelial and smooth muscle cells of the bronchi. No positive signals were observed in $\mathrm{p}^{2} 2 \mathrm{phox}^{-/-}$mice, confirming the knockout, along with specific reactivity of the antibody (figure 5c). Negative staining is shown in figure 5d. To evaluate the extent of potential interactions, next we investigated the expression pattern of the different p22phox-dependent NADPH oxidase isoforms, catalytic and organisational subunits using real-time PCR in lung homogenates. As evident in figure 5e, p22phox deficiency did not alter the regulation of the NADPH oxidase isoforms nox1, nox 2 and nox4 or the organisational and activating subunits noxo1 and noxal in p22 $\mathrm{phox}^{-/-}$mice. In contrast, other NADPH oxidase subunits such as p67, p47 and p40 showed a trend towards upregulation in the $\mathrm{p} 22 \mathrm{phox}^{-/-}$mice; however, only the $\mathrm{p} 40$ expression reached significance.

\section{p22phox ${ }^{-/}$mice lack a functional NADPH oxidase system}

The transmembrane protein p22phox plays an integral role in scaffolding and in the binding to NOX proteins to form a functional ROS-generating NADPH oxidase. In an effort to explain the negative effects of p22phox deficiency on the sustained phase of HPV, first we measured NADPH levels in the lungs. There was no difference in the total NADPH level between $\mathrm{p}_{2} 2 \mathrm{phox}^{+/+}$and $\mathrm{p} 22 \mathrm{phox}^{-/-}$mice (mean $\mathrm{SEM}$ $55.5 \pm 8.6 \mathrm{pmol} \cdot \mathrm{mg}^{-1}$ versus $48.3 \pm 4.4 \mathrm{pmol} \cdot \mathrm{mg}^{-1}$, respectively) (figure 6a). Next, to address the functional NADPH oxidase system, lung slices were treated with phorbol myristate acetate (PMA), a potent activator 

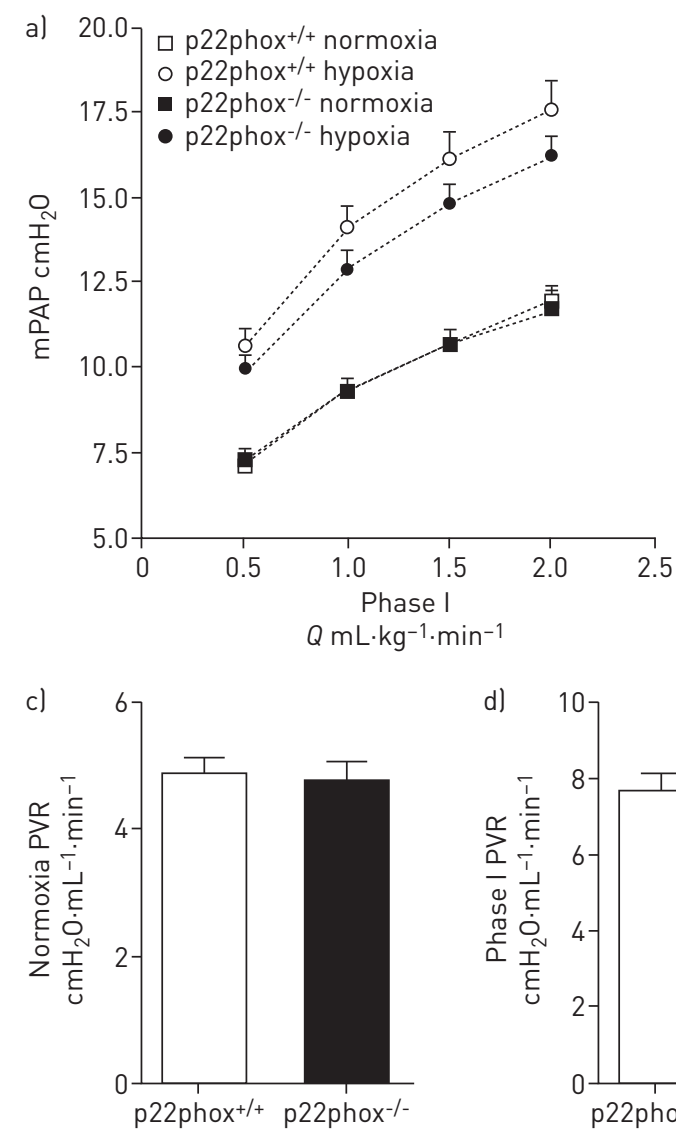
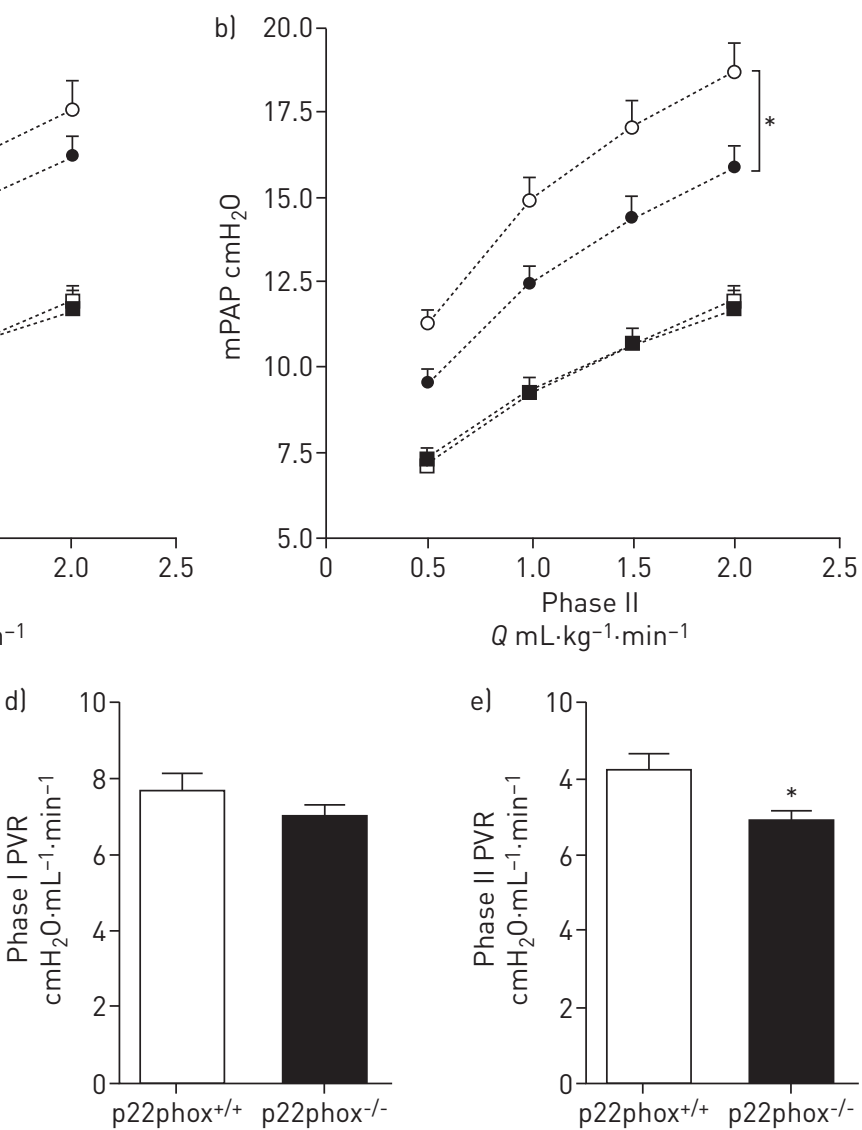

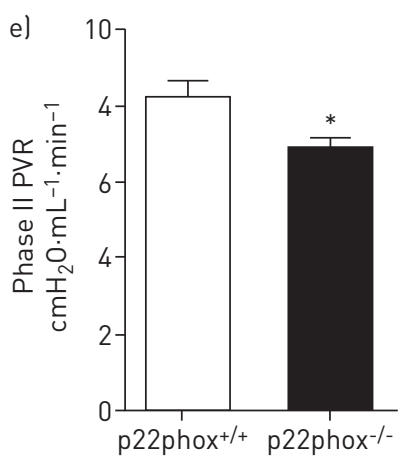

FIGURE 4 p22phox is required for increased vascular resistance denoted as $P-Q$ under the sustained phase of hypoxia. $P-Q$ curves obtained in isolated perfused lungs under al normoxia, or phase I hypoxic pulmonary vasoconstriction (HPV); or b) normoxia or phase II HPV. Changes in pulmonary vascular resistance (PVR) under c) normoxia; d) hypoxia during phase I; or el hypoxia during phase II derived from $P-Q$ curves at the highest perfusion rate $\left(2.0 \mathrm{~mL} \cdot \mathrm{min}^{-1}\right) . \mathrm{n}=6$ for $\mathrm{p} 22 \mathrm{phox}^{+++}$and $\mathrm{n}=8$ for $\mathrm{p} 22 \mathrm{phox}^{-/-}$. mPAP: mean pulmonary arterial pressure. ${ }^{*}: \mathrm{p}<0.05$.

of NADPH oxidase, to generate ROS. The ROS production was detected by cell-permeable dihydroethidium (DHE) and H2DCFDA. As expected, PMA treatment of $\mathrm{p}^{2} 2 \mathrm{phox}^{+/+}$mouse lungs showed markedly increased fluorescence signals indicating superoxide (DHE) and hydrogen peroxide (H2DCFDA) (figure 6b, c and d). Compared with p22phox ${ }^{+/+}$mice, lung slices and single cell suspensions obtained from $\mathrm{p} 22 \mathrm{phox}^{-/-}$mice failed to generate such fluorescence signals in the presence of the NAPDH oxidase activator PMA, reflecting the loss of a functioning NADPH oxidase system in the absence of p22phox.

The sustained phase of HPV is associated with the rho-rho kinase signalling pathway. Next we investigated the rho kinase activation under hypoxia in $\mathrm{p} 22 \mathrm{phox}^{+/+}$and $\mathrm{p} 22 \mathrm{phox}^{-/-}$mice. Figure $6 \mathrm{e}$ shows the hypoxia-induced relative rho kinase activity in the mouse lungs compared with normoxia $(134 \pm 10 \%$ and $98 \pm 4 \%$ for $\mathrm{p}^{2} 2 \mathrm{phox}^{+/+}$and $\mathrm{p} 22 \mathrm{phox}^{-/-}$mice, respectively). These observations suggest that hypoxia was able to activate rho kinase signalling in $\mathrm{p} 22 \mathrm{phox}^{+/+}$mice, but did not yield an increase in $\mathrm{p}_{2} 2 \mathrm{phox}^{-/-}$ mice under the same conditions.

\section{p22phox ${ }^{-/-}$prevents pulmonary vascular remodelling in chronic hypoxia}

To gain insight into whether p22phox deficiency may inhibit hypoxia-induced pulmonary vascular

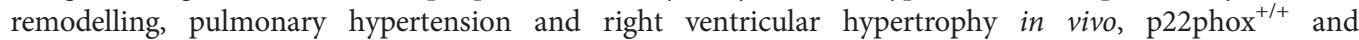

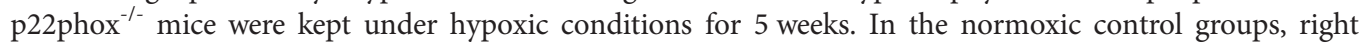
ventricular systolic pressure (RVSP), obtained using right heart catheterisation, showed no significant difference between $\mathrm{p}^{2} 2 \mathrm{phox}^{+/+}$and $\mathrm{p} 22 \mathrm{phox}^{-/-}$littermate controls $(23.0 \pm 0.624$ versus $0 \pm 0.4$, respectively). Similarly, lack of p22phox had no impact on the Fulton index $(0.28 \pm 0.01$ versus $0.27 \pm 0.01)$ or haematocrit values $\left(39.5 \pm 0.7 \%\right.$ versus $38.7 \pm 1.6 \%$ in $\mathrm{p}^{2} 2 \mathrm{phox}^{+/+}$and $\mathrm{p} 22 \mathrm{phox}^{-/-}$mice, respectively). In contrast, after 5 weeks of chronic hypoxia, p22 phox $^{+/+}$mice exhibited a markedly increased RVSP $(35.4 \pm 0.3 \mathrm{mmHg})$, 

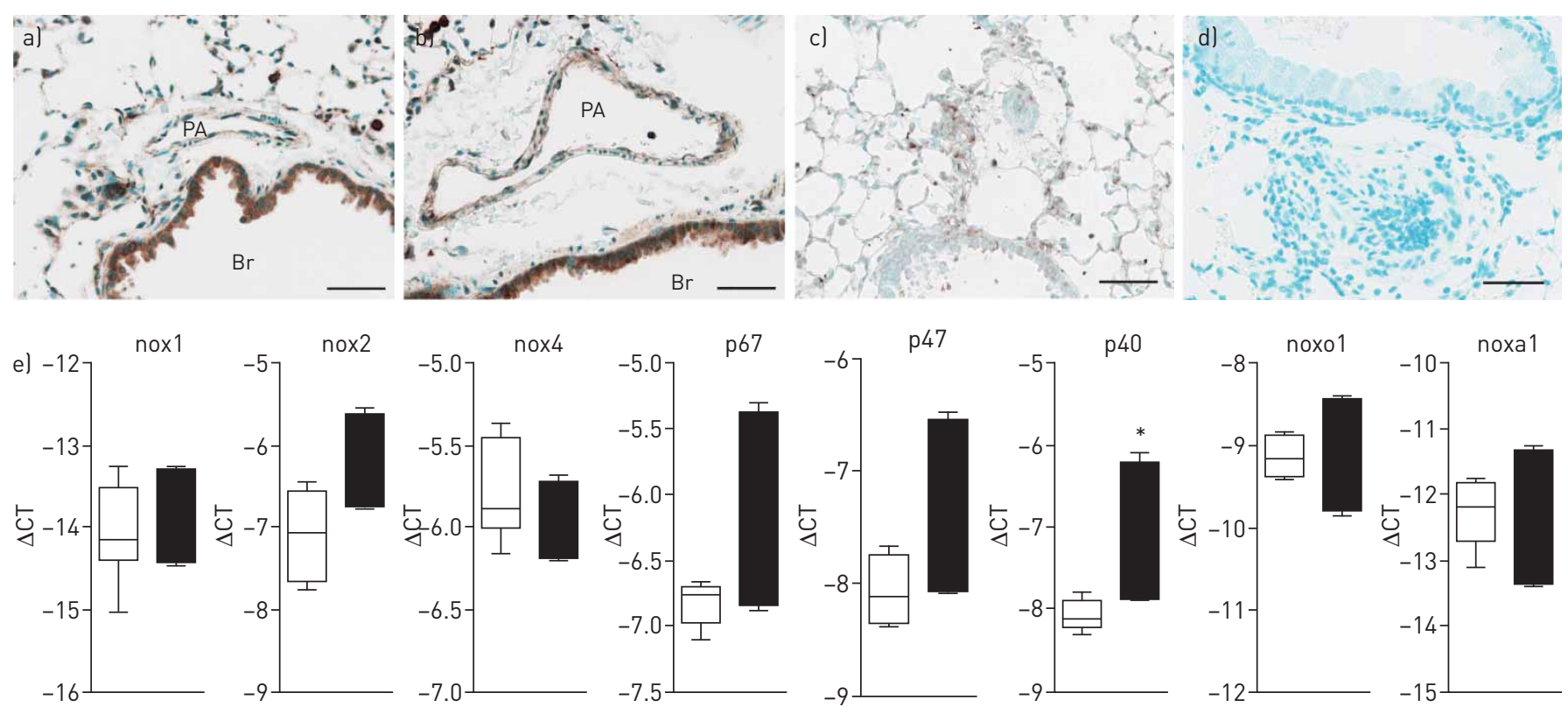

FIGURE 5 p22phox expression in the mouse lung. a), b) Immunostaining of p22phox in the p22phox ${ }^{+/+}$mouse lungs. c) Absence of staining is shown in the lungs of $\mathrm{p} 22 \mathrm{phox}^{-/-}$mice, along with d) negative control. Scale bars $=50 \mu \mathrm{m}$. e) Expression pattern of $\mathrm{p} 22 \mathrm{phox}-\mathrm{dependent}$ NADPH

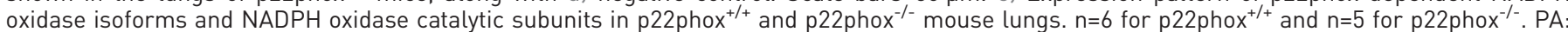
pulmonary arteries; $\mathrm{Br}$ : bronchus; $\Delta \mathrm{CT}$ : $\mathrm{CT}_{\text {avg }}$ (reference gene) - $\mathrm{CT}_{\text {avg }}$ (target gene). $\mathrm{CT}$ : threshold cycle. * ${ }^{*} \mathrm{p}<0.05$.

whereas p22phox ${ }^{-/-}$mice developed a significantly diminished response $(31.9 \pm 1.1 \mathrm{mmHg})$, as shown in

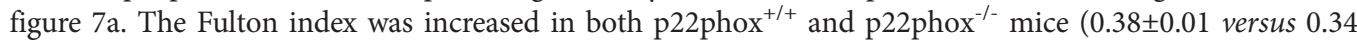
\pm 0.01 ) in response to hypoxia (figure $7 \mathrm{~b}$ ).

Right ventricular (RV) dp/dt is the instantaneous rate of RV pressure rise during early systole. As expected, under normoxic conditions, p22phox deficiency did not alter maximum dp/dt (1814 \pm 84 versus $1959 \pm 115)$ or minimum dp/dt $(-1555 \pm 57$ versus $-1830 \pm 123)$. However, in the chronic hypoxic setting, the $\mathrm{p}^{2} 2 \mathrm{phox}^{-/-}$mice showed a significantly reduced maximum $\mathrm{dp} / \mathrm{dt}(2332 \pm 80$ versus $2706 \pm 31)$ and minimum dp/dt $(-1996 \pm 138$ versus $-2537 \pm 78)$, reflecting mainly the decreased RVSP in p22phox ${ }^{-{ }^{-}}$mice under hypoxia. The right ventricular end-diastolic pressure showed a slight increase under hypoxia without any changes in $\mathrm{p} 22 \mathrm{phox}^{-/-}$mice, and the contractility index remained comparable in $\mathrm{p} 22 \mathrm{phox}^{+/+}$ and $\mathrm{p} 22 \mathrm{phox}^{-1-}$ mice under normoxia and hypoxia (figure 7e-h).

Chronic hypoxia leads to elevated PAP, and induces remodelling of the pulmonary arteries. Vascular remodelling was assessed by the degree of vessel muscularisation (figure 7i). Lack of p22phox did not affect the histological appearance of the pulmonary arteries in mice under normoxic conditions. However, the relative muscularisation was significantly attenuated in $\mathrm{p}^{2} 2 \mathrm{phox}^{-1-}$ mice after the chronic hypoxic challenge compared to the $\mathrm{p}^{2} 2 \mathrm{phox}^{+/+}$mice ( $25 \%$ versus $45 \%$, respectively) (figure $\left.7 \mathrm{j}\right)$. Consequently, the percentage of the nonmuscularised vessels was significantly decreased in $\mathrm{p}^{2} 2 \mathrm{phox}^{+/+}$mice under hypoxia compared to the $\mathrm{p} 22 \mathrm{phox}^{-/-}$mice (55\% versus $76 \%$, respectively) (figure $7 \mathrm{j}$ ), indicating a crucial role of p22phox in hypoxia-induced pulmonary hypertension and vascular remodelling.

\section{Discussion}

The present study shows for the first time that in patients with very severe COPD the NADPH oxidase subunit p22phox is significantly reduced as compared to controls, but that p22phox is preserved in those COPD patients with increased mean PAP, better oxygenation ratio $\left(\mathrm{PO}_{2} / \mathrm{FiO}_{2}\right)$ and lower DLCO. This work is the first to functionally characterise NADPH oxidase, showing that p22phox is important for both phase II (sustained) HPV and chronic hypoxic pulmonary hypertension. These novel findings suggest that p22phox is a key player in COPD and in hypoxic pulmonary vascular remodelling.

Our COPD cohort consisted of a heterogeneous group of patients who underwent lung transplantation due to end-stage disease. Their FEV1 ranged between $9 \%$ pred and $52 \%$ pred, DLCO was between $10 \%$ pred and $41 \%$ pred and PAP ranged from $14 \mathrm{mmHg}$ to $62 \mathrm{mmHg}$. There was no significant correlation between FEV1 and DLCO. In addition, the emphysema score was not significantly correlated with mean PAP or 

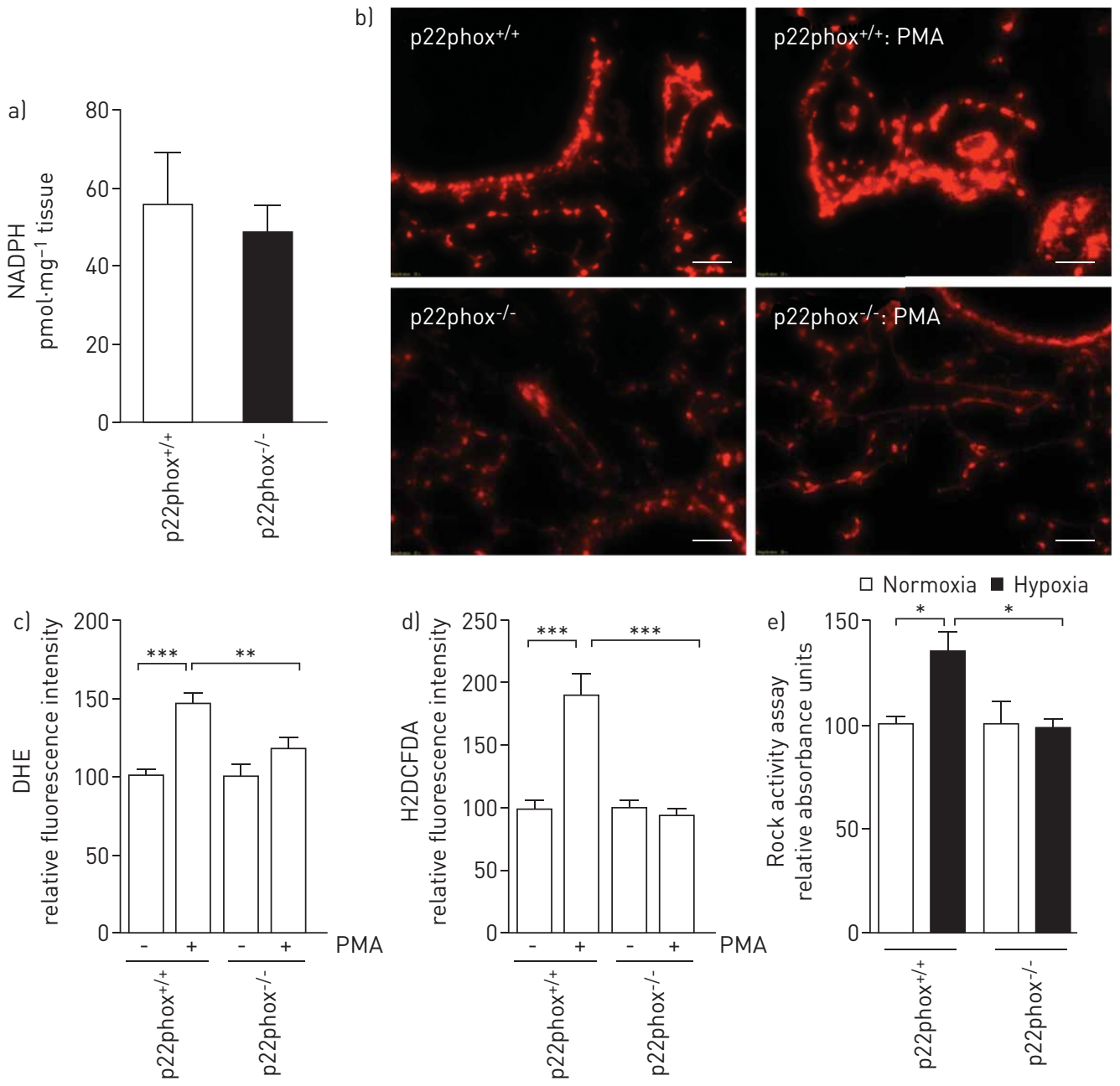

FIGURE 6 p22phox is required for functional NADPH oxidase/Rho kinase axis. a) Total NADPH did not show any differences in the lung homogenates levels in p22phox $^{+/+}$and p22phox ${ }^{-/-}$mice. b, c) p22phox deficiency abolished phorbol myristate acetate (PMA)-induced superoxide production and d) hydrogen peroxide in thin lung slices and single cell suspension of lung. Scale bar=50 $\mu \mathrm{m}$. e) p22phox is required for hypoxia-induced Rho kinase (Rock) activation in lung homogenates. $n=4-5$ in each group. DHE: dihydroethidium. * $p<0.05$.

DLCO; however, this result has to be treated with caution, as the quality of some of the CT scans was limited.

In contrast, mean PAP was strongly negatively correlated with DLCO. This agrees with CHAOUAT et al. [17] who found that in a large cohort of COPD patients, strongly elevated PAP was associated with severely decreased DLCO. This may be due to the fact that DLCO is a measure of the number of perfused and ventilated capillaries and therefore is sensitive to microvascular remodelling, suggesting that pulmonary vascular disease causes both DLCO decrease and PAP increase [18], and is also seen in patients with lung fibrosis [19].

The explanted lungs of the COPD patients expressed significantly less p22phox and p22phox-dependent NADPH oxidase as compared to donor lungs. To our surprise, this finding was not associated with remodelling of the small pulmonary arteries, as DLCO was strongly negatively correlated with p22phox, i.e. the p22phox loss was only major in those COPD patients with diminished HPV and a low PAP, but p22phox was nearly completely preserved in those with preserved HPV and elevated PAP. However, p22phox was significantly positively correlated with mean PAP and oxygenation ratio. This may suggest that patients preserving p22phox despite severe COPD will preserve HPV, and may survive until they have reached extremes of lung parenchymal destruction, which is reflected in extremely low DLCO values (figure 2c).

The expression of p22phox was reduced not only on pulmonary arteries, but also in the whole lung. When we compared the p22phox expression in bronchi between COPD patients and controls we found a significant downregulation in the COPD cases. This finding may be clinically relevant, because p22phox 

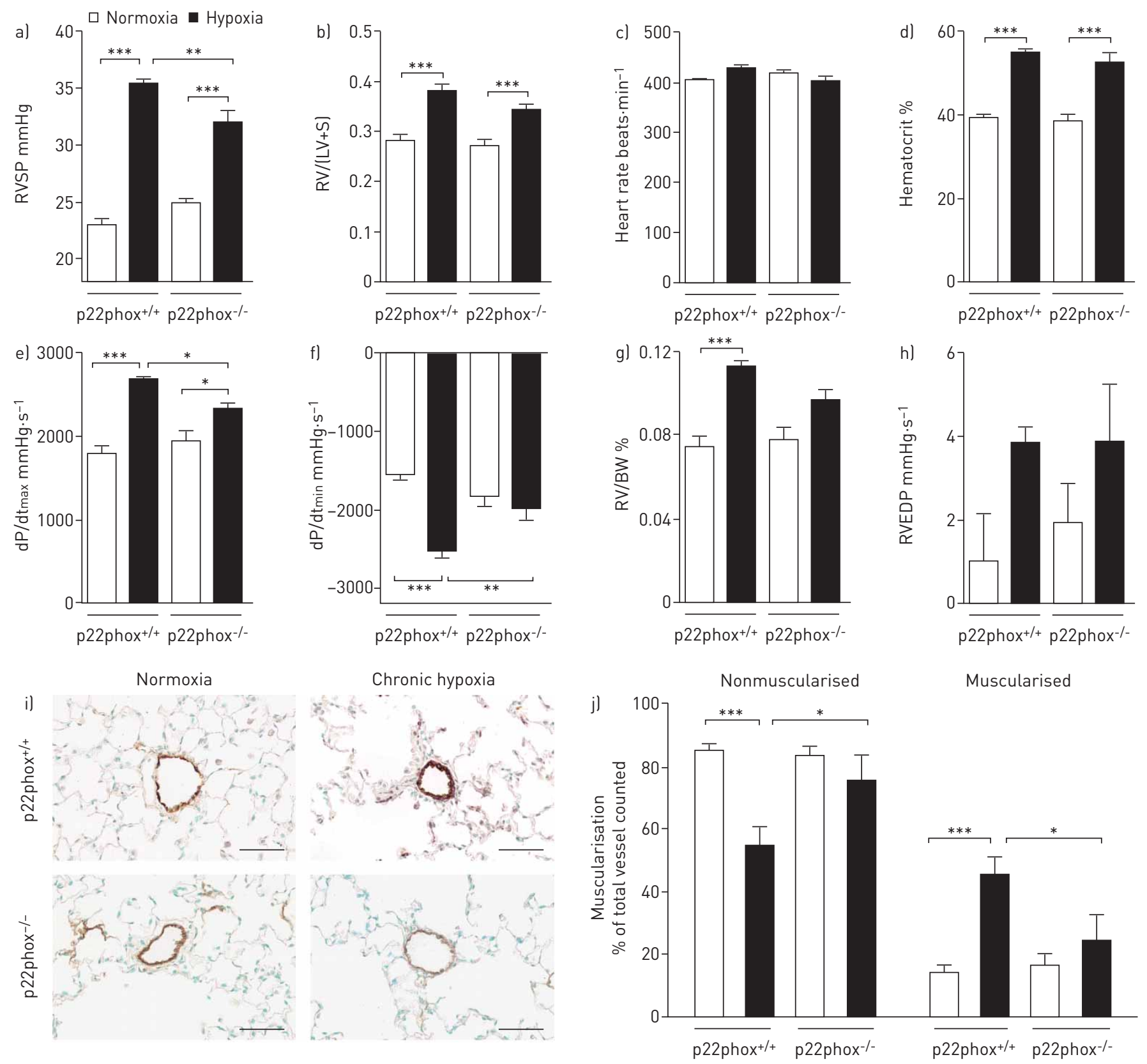

FIGURE 7 Lack of p22phox ${ }^{-/-}$attenuates pulmonary vascular remodelling under chronic hypoxia. Data showing the results obtained after 5 weeks

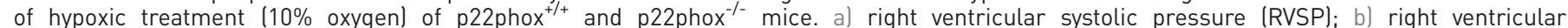
hypertrophy; c) heart rate; d) haematocrit levels. Detailed haemodynamic parameters are given as el maximum rate of rise of RV pressure (dP/dtmax); f) minimum rate of rise of RV pressure (dP/dtmin); g) contractility index; and h) right ventricular end-diastolic pressure (RVEDP).

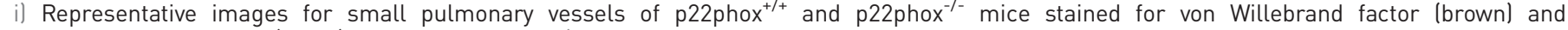
$\alpha$-smooth-muscle actin (violet). Scale bar $=60 \mu \mathrm{m}$. j) Degree of muscularisation of pulmonary vessels. BW: body weight. $n=6-11$ in each group. ${ }^{*}: p<0.05 ;{ }^{* *}: p<0.01 ;{ }^{* *}: p<0.001$.

plays an important role in the anti-infective defence mechanism [20] and COPD is strongly related to infectious complications.

In our study, we provide a comprehensive investigation of a Nox protein in all stages of hypoxia. More importantly, we investigate a subunit which is essential for the function of nox1-4 proteins by a direct interaction at the protein level. We demonstrate that p22phox is necessary for the hypoxia-induced increase in PAP and PVR during the (sustained) phase II of HPV, but not for the short, (acute) phase I of HPV in the murine model. This observation could be explained in part by the reduced ability of $\mathrm{p}^{2} 2 \mathrm{phox}^{-/-}$mice to generate ROS in order to activate the rho-rho kinase system under hypoxia. Here we 
provide evidence that the loss of p22phox results in a significant reduction of pulmonary hypertension, mirrored in reduced RVSP and decreased vascular remodelling.

The role of HPV in matching ventilation and perfusion in the lungs has been recognised for a long time. According to prior investigations, endothelial and smooth muscle cells of the small pulmonary arteries are involved in this process $[8,21,22]$. In addition, it has been reported that capillary endothelial cells are required for the longitudinal propagation of HPV in the intact lung [23]. Proposed mechanisms for oxygen-sensing in HPV include the redox, ROS and energy state/AMP-activated protein kinase hypothesis [8]. In all, changing levels of ROS take a central role. The two major sources of ROS production, mitochondria and NADPH oxidase, are well described in the pulmonary vasculature. For the acute phase of HPV, ROS derived from the complex III of the mitochondria may be involved [24]. The role of NADPH oxidase in HPV was assessed mainly by inhibitors [25], and only a few studies applied hypoxia to knockout animals. Neither Nox $2^{-/-}$nor Nox $4^{-/-}$mice demonstrated a change in phenotype related to HPV $[26,27]$. Only lack of p47phox attenuated the acute phase of HPV significantly, notwithstanding that the effect was very small; however, no changes could be observed in the sustained phase of HPV [25]. gp91 phox $^{-/-}$animals seemed to be protected against chronic hypoxia [28], although this model did not show any changes under acute hypoxic challenge $[25,26]$. To our knowledge, our study is the first to establish the role of NADPH oxidase for phase II HPV, as well as for chronic hypoxic pulmonary hypertension, using the essential protein p22phox responsible for building a functional ROS-producing NADPH oxidase.

Phase I of HPV is mediated by the closure of potassium channels and subsequent calcium influx and/or by the release of calcium from the sarcoplasmic reticulum [29], followed by repletion through store-operated channels and/or by increased calcium influx into smooth muscle cells through L-type calcium channels independent of the membrane potential and/or by promoting calcium sensitisation [30, 31]. In our study, p22 phox $^{-/-}$mice did not show a significant reduction in the acute phase of HPV, and this result is further supported by the fact that the $\mathrm{p}^{2} 2 \mathrm{phox}^{-1-}$ mice did not have any decrease in the vasoconstrictor response evoked by high potassium chloride. This finding reinforces the notion that there is no difference in potassium channel function between $\mathrm{p} 22 \mathrm{phox}^{+/+}$and $\mathrm{p} 22 \mathrm{phox}^{-/-}$animals, and the potassium channel inhibition is not reliant on the p22phox-dependent NADPH oxidase activation. Collectively, these results indicate that NADPH oxidase is not required for the acute phase I of HPV.

The second, sustained phase II of HPV is mainly dependent on endothelium and on rho kinase [21, 32, 33]. Studies performed on rat intrapulmonary arteries and the isolated perfused lung have shown that rho-associated kinase plays a pivotal role in the generation of the sustained phase [34, 35]. Additionally, the rho kinase-dependent calcium sensitisation has been reported to contribute to the sustained HPV [21]. Here we show that lack of p22phox resulted in a skewed HPV. According to previous investigations, superoxide could modulate the activation of rho and rho-mediated kinase [36]. Therefore, we performed rho kinase activation studies under hypoxia and found that $222 \mathrm{phox}^{-/-}$mice failed to generate NADPH oxidase-dependent ROS, and thus were unable to activate rho kinase. Our observation is supported by a previous study, describing the lack of the NADPH oxidase-mediated oxidative burst in the neutrophils in $\mathrm{p}^{2} 2 \mathrm{phox}^{-/-}$mice, which leads to susceptibility to bacterial infection in the lung [37]. Therefore, the

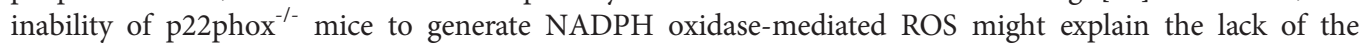
hypoxia-mediated activation of rho kinase.

The participation of members of the NADPH oxidase family is well documented in pathophysiological mechanisms responsible for pulmonary hypertension, e.g. in human pulmonary hypertension and in different animal models of pulmonary hypertension. In particular, the Nox4 isoform is upregulated in the chronic hypoxia-induced pulmonary hypertension model, as well as in human idiopathic pulmonary arterial hypertension samples [13], whereas upregulation of the Nox1 isoform is reported in the monocrotaline model of pulmonary hypertension [38]. Since alveolar hypoxia is considered to be the major contributor resulting in HPV and pulmonary arterial remodelling [8], and in our cohort of COPD patients, p22phox was associated with an elevated mean pulmonary pressure, we investigated the effect of the lack of p22phox under chronic hypoxia in a mouse model. Our results show that $\mathrm{p} 22 \mathrm{phox}^{-/-}$mice are protected from chronic hypoxia-induced vascular remodelling. Most importantly, the present study investigated a p22phox protein comprehensively in each of the acute, sustained and chronic phases of hypoxia.

We are aware of the limitations of our study. We included a relatively small number of end-stage COPD patients with a wide range of parenchymal and vascular lesions. By requiring that the $\mathrm{FEV} 1$ be $<55 \%$ pred in this cohort, we assured that significant COPD was present. Since this is a hypothesis-generating study, validation will require an independent study population. Another limitation of our study is that differences in activated macrophages and neutrophils between p22phox-deficient mice and controls could have 
influenced lung pathology other than vascular remodelling. In addition, mouse HPV may differ from human HPV in several aspects. Validation of the results in different knockout species would be valuable, but such models are not available. Moreover, our chronic model reflects only the vascular component of the disease under hypoxia and does not cover other aspects such as alveolar destruction and emphysema.

In conclusion, our results delineate an important role of p22phox-dependent NADPH oxidase in regulating pulmonary vascular tone under hypoxia and show that NADPH oxidase is operative under physiological conditions. p22phox expression is associated with the vascular COPD phenotype. The modification of the p22phox pathway may open important avenues for therapy of pulmonary vascular remodelling on the one hand and oxygenation problems on the other. p22phox might also have diagnostic value as a predictor of the vascular COPD phenotype. These observations contribute to a growing body of evidence suggesting NADPH oxidase as an important player in lung physiology and pathology.

\section{Acknowledgements}

We would like to thank Sabine Halsegger (Institute of Physiology, Medical University of Graz, Graz, Austria), Elisabeth Blanz (Ludwig Boltzmann Institute for Lung Vascular Research, Graz) and Simone Tischler (Dept of Anaesthesiology and Intensive Care Medicine, Medical University of Graz) for their excellent technical support.

Authors' contributions are as follows. Conception and design: C. Nagaraj, H. Olschewski, A. Olschewski; research analysis and interpretation: C. Nagaraj, C. Tabeling, M. Pienn, B.M. Nagy, P.P. Jain, L.M. Marsh, R. Papp, M. Witzenrath; sample acquisition, collection of patients' clinical information and confirmation of the diagnosis of patients included in the study: A. Olschewski; B. Ghanim, W. Klepetko, S. Heschl, H. Olschewski, A. Olschewski; drafting the manuscript for important intellectual content: C. Nagaraj, E.K. Weir, G. Kwapiszewska, H. Olschewski, A. Olschewski; all authors read and approved the manuscript.

\section{References}

1 Vestbo J, Hurd SS, Agustí AG, et al. Global strategy for the diagnosis, management, and prevention of chronic obstructive pulmonary disease: GOLD executive summary. Am J Respir Crit Care Med 2013; 187: 347-365.

2 Thabut G, Ravaud P, Christie JD, et al. Determinants of the survival benefit of lung transplantation in patients with chronic obstructive pulmonary disease. Am J Respir Crit Care Med 2008; 177: 1156-1163.

3 Kasahara Y, Tuder RM, Taraseviciene-Stewart L, et al. Inhibition of VEGF receptors causes lung cell apoptosis and emphysema. J Clin Invest 2000; 106: 1311-1319.

4 Seimetz M, Parajuli N, Pichl A, et al. Inducible NOS inhibition reverses tobacco-smoke-induced emphysema and pulmonary hypertension in mice. Cell 2011; 147: 293-305.

5 Hoffmann J, Wilhelm J, Marsh LM, et al. Distinct differences in gene expression patterns in pulmonary arteries of patients with chronic obstructive pulmonary disease and idiopathic pulmonary fibrosis with pulmonary hypertension. Am J Respir Crit Care Med 2014; 190: 98-111.

6 Seeger W, Adir Y, Barberà JA, et al. Pulmonary hypertension in chronic lung diseases. J Am Coll Cardiol 2013; 62: Suppl. 25, D109-D116.

7 Weir EK, López-Barneo J, Buckler KJ, et al. Acute oxygen-sensing mechanisms. N Engl J Med 2005; 353: 2042-2055.

8 Sylvester JT, Shimoda LA, Aaronson PI, et al. Hypoxic pulmonary vasoconstriction. Physiol Rev 2012; 92: 367-520.

9 Weir EK, Cabrera JA, Mahapatra S, et al. The role of ion channels in hypoxic pulmonary vasoconstriction. Adv Exp Med Biol 2010; 661: 3-14.

10 Sommer N, Strielkov I, Pak O, et al. Oxygen sensing and signal transduction in hypoxic pulmonary vasoconstriction. Eur Respir J 2016; 47: 288-303.

11 Brandes RP, Weissmann N, Schröder K. Nox family NADPH oxidases: molecular mechanisms of activation. Free Radic Biol Med 2014; 76: 208-226.

12 Bedard K, Krause KH. The NOX family of ROS-generating NADPH oxidases: physiology and pathophysiology. Physiol Rev 2007; 87: 245-313.

13 Mittal M, Roth M, König P, et al. Hypoxia-dependent regulation of nonphagocytic NADPH oxidase subunit NOX4 in the pulmonary vasculature. Circ Res 2007; 101: 258-267.

14 Zalba G, Beaumont FJ, San José G, et al. Vascular NADH/NADPH oxidase is involved in enhanced superoxide production in spontaneously hypertensive rats. Hypertension 2000; 35: 1055-1061.

15 Yao H, Edirisinghe I, Yang SR, et al. Genetic ablation of NADPH oxidase enhances susceptibility to cigarette smoke-induced lung inflammation and emphysema in mice. Am J Pathol 2008; 172: 1222-1237.

16 Ambasta RK, Kumar P, Griendling KK, et al. Direct interaction of the novel Nox proteins with p22phox is required for the formation of a functionally active NADPH oxidase. J Biol Chem 2004; 279: 45935-45941.

17 Chaouat A, Bugnet AS, Kadaoui N, et al. Severe pulmonary hypertension and chronic obstructive pulmonary disease. Am J Respir Crit Care Med 2005; 172: 189-194.

18 Minai OA, Fessler H, Stoller JK, et al. Clinical characteristics and prediction of pulmonary hypertension in severe emphysema. Respir Med 2014; 108: 482-490.

19 Hamada K, Nagai S, Tanaka S, et al. Significance of pulmonary arterial pressure and diffusion capacity of the lung as prognosticator in patients with idiopathic pulmonary fibrosis. Chest 2007; 131: 650-656.

20 Lassègue B, Griendling KK. NADPH oxidases: functions and pathologies in the vasculature. Arterioscler Thromb Vasc Biol 2010; 30: 653-661.

21 Evans AM, Hardie DG, Peers C, et al. Hypoxic pulmonary vasoconstriction: mechanisms of oxygen-sensing. Curr Opin Anaesthesiol 2011; 24: 13-20.

22 Weissmann N, Sommer N, Schermuly RT, et al. Oxygen sensors in hypoxic pulmonary vasoconstriction. Cardiovasc Res 2006; 71: 620-629. 
23 Wang L, Yin J, Nickles HT, et al. Hypoxic pulmonary vasoconstriction requires connexin 40-mediated endothelial signal conduction. J Clin Invest 2012; 122: 4218-4230.

24 Waypa GB, Marks JD, Guzy RD, et al. Superoxide generated at mitochondrial complex III triggers acute responses to hypoxia in the pulmonary circulation. Am J Respir Crit Care Med 2013; 187: 424-432.

25 Weissmann N, Zeller S, Schäfer RU, et al. Impact of mitochondria and NADPH oxidases on acute and sustained hypoxic pulmonary vasoconstriction. Am J Respir Cell Mol Biol 2006; 34: 505-513.

26 Archer SL, Reeve HL, Michelakis E, et al. $\mathrm{O}_{2}$ sensing is preserved in mice lacking the gp91 phox subunit of NADPH oxidase. Proc Natl Acad Sci USA 1999; 96: 7944-7949.

27 Kleinschnitz C, Grund H, Wingler K, et al. Post-stroke inhibition of induced NADPH oxidase type 4 prevents oxidative stress and neurodegeneration. PLoS Biol 2010; 8: 10.1371/journal.pbio.1000479.

28 Liu JQ, Zelko IN, Erbynn EM, et al. Hypoxic pulmonary hypertension: role of superoxide and NADPH oxidase (gp91phox). Am J Physiol Lung Cell Mol Physiol 2006; 290: L2-L10.

29 Post JM, Hume JR, Archer SL, et al. Direct role for potassium channel inhibition in hypoxic pulmonary vasoconstriction. Am J Physiol 1992; 262: C882-C890.

30 del Valle-Rodríguez A, López-Barneo J, Ureña J. $\mathrm{Ca}^{2+}$ channel-sarcoplasmic reticulum coupling: a mechanism of arterial myocyte contraction without $\mathrm{Ca}^{2+}$ influx. EMBO J 2003; 22: 4337-4345.

31 Vadula MS, Kleinman JG, Madden JA. Effect of hypoxia and norepinephrine on cytoplasmic free $\mathrm{Ca}^{2+}$ in pulmonary and cerebral arterial myocytes. Am J Physiol 1993; 265: L591-L597.

32 Connolly MJ, Prieto-Lloret J, Becker S, et al. Hypoxic pulmonary vasoconstriction in the absence of pretone: essential role for intracellular $\mathrm{Ca}^{2+}$ release. J Physiol 2013; 591: 4473-4498.

33 Robertson TP, Aaronson PI, Ward JP. $\mathrm{Ca}^{2+}$ sensitization during sustained hypoxic pulmonary vasoconstriction is endothelium dependent. Am J Physiol Lung Cell Mol Physiol 2003; 284: L1121-L1126.

34 Chi AY, Waypa GB, Mungai PT, et al. Prolonged hypoxia increases ROS signaling and RhoA activation in pulmonary artery smooth muscle and endothelial cells. Antioxid Redox Signal 2010; 12: 603-610.

35 Duong-Quy S, Bei Y, Liu Z, et al. Role of Rho-kinase and its inhibitors in pulmonary hypertension. Pharmacol Ther 2013; 137: 352-364.

36 Knock GA, Snetkov VA, Shaifta Y, et al. Superoxide constricts rat pulmonary arteries via Rho-kinase-mediated $\mathrm{Ca}^{2+}$ sensitization. Free Radic Biol Med 2009; 46: 633-642.

37 Nakano Y, Longo-Guess CM, Bergstrom DE, et al. Mutation of the Cyba gene encoding p22phox causes vestibular and immune defects in mice. J Clin Invest 2008; 118: 1176-1185.

38 Veit F, Pak O, Egemnazarov B, et al. Function of NADPH oxidase 1 in pulmonary arterial smooth muscle cells after monocrotaline-induced pulmonary vascular remodeling. Antioxid Redox Signal 2013; 19: 2213-2231. 